\title{
Time-to-recovery After Cesarean Section Delivery Among Women who Gave birth through Cesarean Section at Hawassa University Comprehensive Specialized Hospital, south Ethiopia: A Prospective Cohort Study
}

Anteneh Fikrie ( $\square$ antenehfikrie3@gmail.com )

Bule Hora University

Rahel Zeleke

Pharma College Hawassa Campus

Henok Bekele

Pharma College Hawassa Campus

Wengelawit Seyoum

Pharma College Hawassa Campus

Dejene Hailu

Hawassa University

Research Article

Keywords: Time to recovery, Survival Status, Predictors, Ethiopia

Posted Date: April 30th, 2021

DOI: https://doi.org/10.21203/rs.3.rs-442628/v1

License: @ (1) This work is licensed under a Creative Commons Attribution 4.0 International License. Read Full License 


\section{Abstract}

Background: Despite the progressive increment of caesarean section rates worldwide over the last decades; still the trend has not been accompanied by significant maternal or perinatal benefits. Moreover, information on the quality of the service, as measured by timely recovery, is scarce. This study assessed predictors of time-to-recovery after cesarean section delivery among women who gave birth through cesarean section at Hawassa University Comprehensive Specialized Hospital (HU-CSH), southern Ethiopia.

Methods: Institution based prospective cohort study was conducted on 381 randomly selected women who gave birth by cesarean section in HU-CSH during the follow up period. Pre-tested structured questionnaire was used to collect the data. Data were analyzed using Kaplan Meir (KM) curve, Log rank test and CoxProportional hazard model. The outputs of the bivariable and multivariable Cox model are presented using Adjusted Hazard Ratio (AHR) with the respective 95\% confidence intervals (Cls).

Results: After a maximum of 19 days of stay, $96.2 \%$ [95\% Cl: $94.04-98.4 \%$ ] of the women were early recovered. The overall median IQR) time of recovery was $2.00(2,3)$ days. The overall incidence density rate (IDR) of recovery in the cohort was 0.34 per Person-days or 2.38 per person-week. On the other hand the overall mean survival time was $3.07(95 \% \mathrm{Cl}$ : $2.75-3.40)$ days. Women who had ANC follow-up (AHR=1.49, 95\%, Cl: 1.05-2.10) and discharge from the wound site (AHR=0.13,95\%, Cl: 0.03-0.56) were identified as significant positive and negative predictors of time-to- recovery after CS delivery respectively.

Conclusion: This study showed that the rate of early recovery was high and is comparable to the global level figures. However, further improving preoperative maternal status, intraoperative follow up and postoperative care is needed to improve early recovery.

\section{Background}

Caesarean section(CS) is the most commonly performed surgical procedures worldwide that effectively prevents maternal and newborn mortality when used for medically indicated reasons [1-3]. However, there is lack of evidence revealing its benefits for women who do not require the procedure [2]. Despite the progressively increased CS rates worldwide over the last decades; still the trend has not been accompanied by significant maternal or perinatal benefits. Conversely, the existing evidence showed that higher rates of CS have been associated with increased maternal and perinatal morbidity [1].

For more than three decades the ideal rate for caesarean sections was estimated to be between $10 \%$ and $15 \%$ [2]. However, nearly $20 \%$ of births were delivered by CS universally of which the vast majority (more than $40 \%$ ) was observed in Latin America and the Caribbean followed by Oceania and North America with prevalence rate of 35\%. In England, 27.8\% of all pregnant women undergo CS to deliver their babies [4]. Likewise, in Ethiopia most recently a prevalence rate of $24.7 \%$ was reported [5]. Many factors had been implicated for the substantial rise of the CS rates [3] such as increase in the prevalence of obesity, multiple pregnancies, and increase in the proportion of nulliparous women or older women, fear of pain, physician factors, increasing fear of medical litigation, as well as organizational, economic and social factors [1]. 
An increasing rise in the rate of CS delivery becomes a major public health concern $[3,6]$. According to a large study result in low and middle income countries; one-fourth of women were died after giving birth through CS [3]. CS is associated with short-term risks such as; blood transfusion, the risks of anesthesia complications, organ injury, infection and long-term risks that can extend many years beyond the current delivery and affect the health of the woman, the child, future pregnancies $[1,2,7,8]$.

Despite raise in rates, cesarean delivery is the single most important factor associated with $5-20$ folds increased postpartum infection than vaginal delivery $[4,9,10]$. Likewise, studies conducted in Ethiopia found that $11-15 \%$ of women who had given birth through CS developed surgical site infection which later leads to delayed recovery $[10,11]$. Moreover, information on the quality of the service, as measured by timely recovery, is scare particularly in the study area. Therefore, this study assessed time-to-recovery after cesarean section delivery and predictors among women who gave birth through cesarean section at Hawassa University Comprehensive Specialized Hospital (HU-CSH), southern Ethiopia.

\section{Methods And Materials}

\section{Study design and settings}

Institution-based prospective cohort study design was conducted from July to August, 2020 at Hawassaa University Comprehensive Specialized Hospital (HU-CSH), Southern Ethiopia. The hospital is located in Hawassa city, the capital of Sidama regional state. It is one of the teaching and specialized and comprehensive hospital in the Southern part of Ethiopia. It has over 400 beds. The averages monthly CS deliveries are estimated to be 200.There are 72 midwives nurses and 7 senior Gynecologist doctors serving in the hospital.

\section{Study population and sample size}

The source population was all women who gave birth through CS in HU-CSH. Sample size was calculated based on double population proportion formula by using Epi info version 7 computer program considering the following assumptions: $95 \% \mathrm{Cl}$, power $80 \%$, ratio of unexposed to exposed $1: 1$ and outcome in exposed $24.63 \%$ and outcome in unexposed $12.2 \%$ [11], with Risk ratio of 2: and $10 \%$ non-response rate. Finally the calculated sample became 381. Consecutive sampling was used to enroll mothers who underwent cesarean section delivery at the study hospital till the estimated sample size was attained.

\section{Data collection procedure and data quality control}

Three trained midwife nurses from Labor and Obstetrics and Gynecology ward and a Public Health Officer were participated in the data collection and supervision, respectively. Both the data collectors and supervisor were trained for two-days on the procedures of data collection. A pretested structured questionnaire which were adapted by reviewing different peer reviewed articles were used to collect the data $[5,12]$. Data like socio-demographic characteristics (age, marital status, residences, BMI, educational 
status, religion, family income, number of children's, source of referral), medical and obstetrics characteristics (ANC visits, number of ANC visits, HTN, DM, HIV/AIDs, anemia, blood transfusion, history of abortion and gestational age during CS), Pre, intra and post-operative characteristics (Pervious history of CS, number of CS delivery, Types skin incision, breast feeding, type of anesthesia used, presence of discharge from wound site, mobility after CS delivery), the date of CS procedure done and discharge date were obtained by the face-to-face interview, individual maternal records and referral notes review.

\section{Data processing and analysis}

The data were thoroughly cleaned, coded and then entered in to EPINFO version 3.5.3 and exported to the Statistical Package for Social Science (SPSS) version 20 for analysis. Descriptive analysis was run to assess missing values and presence of outliers. The Kolmogrov Smirnov test of normality was used to check the normality of distributions for continuous variables. The dependent variable was time-to-recovery after CS delivery. The recovery time after CS delivery was dichotomized into early recovered or censored. Those who stayed $\leq 4$ days after the CS delivery were taken as early recovered [13]; whereas the others were regarded as censored (late recovered) based on thier length of stay. Length of stay (LOS) is the number of days the women stayed in the hospital from the date CS was done until the womens develop event of interest (early recovery) or censored (late recovery). Length of stay was computed using the difference between the date of discharge and date of CS procedure done.

Multicollinearity test was carried to see the correlation between the independent variables and no multicollinearity between independent variables was witnessed (Variance inflation factor $<10$ ). Data were described using frequency distribution and measures of central tendency and dispersion. Kaplan- Maier Curve and Long rank test were used to estimate cumulative survival probability and to compare survival status probablity across different groups. Cox proportional-hazard regression were used to adjust the potential cofounding varables and identify predictors of time-to-recovery. Variables with $p$-value less than 0.25 during bivariate analysis were considered as a candidate for multivariable analysis. The assumption of proportional hazard was graphically evaluated by log-minus-log survival curve. Adjusted hazard ratio (AHR) with 95\% confidence interval (Cl) were used to present the output of the analysis [14].

\section{Results}

\section{Socio-demographic characteristics of participants}

From a total of 381 randomly selected womens delivered by CS, the data of 369 with response rate of $96.8 \%$. All most all, 365 (98.9\%) of women were married. Majority 307 (83.2\%) of the women came from urban areas. The mean $( \pm S D)$ age of the participants was $27( \pm 3.5)$ years and the majority $(90.2 \%)$, were less than the age of thirty years. The majority of women, 127 (34.4\%) and $193(52.3 \%)$ have college and above level of education and housewife in thier occupation respectively. Nearly half, $176(47.7 \%)$ of the participants family have monthly income of $63.06-126.13 \$$ range. More than three-fourth, $277(76.2 \%)$ of 
the women have source of referral and the majority, 205(74\%) of them were referred from health center (Table 1) 
Table 1

Socio-demographic characteristics of participants delivered at HUCSH, 2020.

\begin{tabular}{|c|c|c|c|}
\hline Variable & & Frequency & Percent (\%) \\
\hline \multirow[t]{4}{*}{ Age in years } & $\leq 20$ & 22 & 6 \\
\hline & $21-25$ & 99 & 26.8 \\
\hline & $26-30$ & 212 & 57.5 \\
\hline & $\geq 31$ & 36 & 9.8 \\
\hline \multirow[t]{4}{*}{ Educational level } & No formal education & 26 & 7 \\
\hline & Primary education & 94 & 25.5 \\
\hline & Secondary education & 122 & 31.1 \\
\hline & College and above & 127 & 34.4 \\
\hline \multirow[t]{3}{*}{ Religion } & Orthodox & 110 & 29.8 \\
\hline & Protestant & 186 & 50.4 \\
\hline & Muslim & 73 & 19.8 \\
\hline \multirow[t]{2}{*}{ Residence } & Urban & 307 & 83.2 \\
\hline & Rural & 62 & 16.8 \\
\hline \multirow[t]{4}{*}{ Occupation of mother } & House wife & 193 & 52.3 \\
\hline & Private employee & 58 & 15.7 \\
\hline & Governmental employee & 79 & 21.4 \\
\hline & Others@ & 39 & 10.6 \\
\hline \multirow[t]{4}{*}{ Family monthly income in USD } & $63.06 \$$ & 42 & 11.4 \\
\hline & 63.06-126.13\$ & 176 & 47.7 \\
\hline & $126.13-252.27 \$$ & 125 & 33.9 \\
\hline & $252.27 \$$ & 26 & 7 \\
\hline \multirow[t]{3}{*}{ Number of children } & $<2$ & 259 & 70.2 \\
\hline & $2-3$ & 80 & 21.7 \\
\hline & $\geq 4$ & 30 & 8.1 \\
\hline \multirow[t]{2}{*}{ Do you have source of referral } & Yes & 277 & 76.2 \\
\hline & No & 92 & 23.8 \\
\hline
\end{tabular}

@ Merchant, student, unemployed $(n=369)$ 


\begin{tabular}{|c|c|c|c|}
\hline Variable & & Frequency & Percent (\%) \\
\hline \multirow[t]{2}{*}{ The source of referral $(n=277)$} & Health center & 205 & 74 \\
\hline & Hospital & 72 & 26 \\
\hline \multirow[t]{2}{*}{ BMI $(\mathrm{kg} / \mathrm{m} 2)$} & Normal & 264 & 71.5 \\
\hline & Overweight & 105 & 28.5 \\
\hline \multicolumn{4}{|c|}{ @ Merchant, student, unemployed $(n=369)$} \\
\hline
\end{tabular}

The vast majority of participants, 328(88.9\%) had at least one ANC visits. Accordingly, $31.1 \%$ and $57.7 \%$ of the women had 1-3 and $\geq$ Four ANC visits respectively. The mean ( \pm SD) Gestational age (GA) during delivery was 37.9 ( \pm 1.72 ) weeks and $24.7 \%$ had GA of less than 37 weeks. Regarding chronic diseases; about $3.5 \%, 2.7 \%$, and $1.9 \%$ of the women had hypertension, diabettus melites and HIV/AIDs respectively. Likewise, nearly one-in-five, $19.2 \%$ of women were diagnosed with anemia and $1.6 \%$ of them recieved blood transfussion. (Table 2). 
Table 2

Medical and obstetrics characteristics of the women on ppredictors of time-to-recovery from cesarean section delivery among women who gave birth by CS at HUCSH, $2020(\mathrm{n}=369)$.

\begin{tabular}{|c|c|c|c|}
\hline Variable & Category & Frequency & Percent \\
\hline \multirow[t]{2}{*}{ ANC visit } & Yes & 328 & 88.9 \\
\hline & No & 41 & 11.1 \\
\hline \multirow[t]{3}{*}{ Number of visits $(n=328)$} & No visits & 41 & 11.1 \\
\hline & $1-3$ times & 115 & 31.2 \\
\hline & $\geq$ Four times & 213 & 57.7 \\
\hline \multirow[t]{2}{*}{ Hypertension } & Yes & 13 & \\
\hline & No & 356 & \\
\hline \multirow[t]{2}{*}{ Diabetes mellitus } & Yes & 10 & \\
\hline & No & 359 & \\
\hline \multirow[t]{2}{*}{ HIV/AIDs } & Yes & 7 & \\
\hline & No & 362 & \\
\hline \multirow[t]{2}{*}{ Anemia } & Yes & 71 & 19.2 \\
\hline & No & 298 & 80.8 \\
\hline \multirow[t]{2}{*}{ Blood transfusion } & Yes & 6 & 1.6 \\
\hline & No & 369 & 98.4 \\
\hline \multirow[t]{2}{*}{ History of abortion } & Yes & 51 & 13.8 \\
\hline & No & 318 & 86.2 \\
\hline \multirow[t]{2}{*}{ Number of abortions $(n=51)$} & One times & 45 & 88.2 \\
\hline & $\geq$ two times & 6 & 11.8 \\
\hline \multirow[t]{3}{*}{ GA at during $\mathrm{CS}$} & $<37$ weeks & 91 & 24.7 \\
\hline & $37-40$ weeks & 251 & 68 \\
\hline & $>40$ weeks & 27 & 7.3 \\
\hline
\end{tabular}

\section{Pre, intra and post-operative characteristics of the women}

One-in-seven, $(15.4 \%)$ of the women had previous history of CS delivery; whereas he majority $(84.4 \%)$ of them had one time exposure including the current. The vast majority $94.6 \%$ of women has undergone transverse type's skin incision. About $3 \%$ of the women experienced discharge from wound site (Table 3). 
Table 3

Pre, intra and post-operative characteristics of the women on predictors of time-torecovery from cesarean section delivery among women who gave birth by CS at $\mathrm{HUCSH}$, $2020(n=369)$.

\begin{tabular}{|c|c|c|c|}
\hline Variables & Category & Frequency & Percent (\%) \\
\hline \multirow[t]{2}{*}{ Pervious history of CS } & Yes & 57 & 15.4 \\
\hline & No & 312 & 84.6 \\
\hline \multirow[t]{3}{*}{ Number of CS done including the current } & One time & 312 & 84.4 \\
\hline & Two time & 46 & 12.5 \\
\hline & $\geq$ Three time & 11 & 3 \\
\hline \multirow[t]{2}{*}{ Types skin incision } & Transvers & 349 & 94.6 \\
\hline & Vertical & 20 & 5.4 \\
\hline \multirow[t]{2}{*}{ Breast feeding } & Yes & 352 & 95.4 \\
\hline & No & 17 & 4.6 \\
\hline \multirow[t]{2}{*}{ Type of anesthesia used } & General & 23 & 6.2 \\
\hline & Local & 346 & 93.8 \\
\hline \multirow[t]{2}{*}{ Discharge from wound site } & Yes & 11 & 3 \\
\hline & No & 358 & 97 \\
\hline \multirow[t]{2}{*}{ Bad odor discharge } & Yes & 9 & 2.4 \\
\hline & No & 360 & 97.8 \\
\hline \multirow[t]{2}{*}{ Mobility after CS } & Yes & 367 & 99.5 \\
\hline & No & 2 & 0.5 \\
\hline \multirow[t]{2}{*}{ Indication for CS } & Maternal & 185 & 50.1 \\
\hline & Fetal & 184 & 49.9 \\
\hline
\end{tabular}

\section{Time to recovery from Cesarean section delivery}

In this study the proportion of timely recovery (within 4 days) is $96.2 \%$ [95\% Cl: $94.04-98.4 \%$ ]. The overall median (IQR) time-to-recovery was $2.00(2,3)$ days. The overall incidence density rate (IDR) of timely recovery was calculated using person-days of follow up as a denominator for the entire cohort. Thus, 369 study participants were followed for 1,042 person-days of observation. Henceforth, the IDR 0.34 per persondays or 2.38 per person-week. Whereas, the cumulative probability of early recovery at the 1 st and 4 th day was 0.995 and 0.038 respectively. The overall mean survival time was $3.07(95 \% \mathrm{Cl}: 2.75-3.40)$ days (Table 4). 
Table 4

Life table analysis of severely among women who gave birth by CS delivery at HUCSH, 2020

\begin{tabular}{|c|c|c|c|c|c|c|c|}
\hline $\begin{array}{l}\text { Interval } \\
\text { Start } \\
\text { Time }\end{array}$ & $\begin{array}{l}\text { Number } \\
\text { Entering } \\
\text { Interval }\end{array}$ & $\begin{array}{l}\text { Number } \\
\text { Withdrawing } \\
\text { during } \\
\text { Interval }\end{array}$ & $\begin{array}{l}\text { Number } \\
\text { Exposed } \\
\text { to Risk }\end{array}$ & $\begin{array}{l}\text { Number } \\
\text { of } \\
\text { Terminal } \\
\text { Events }\end{array}$ & $\begin{array}{l}\text { Proportion } \\
\text { Terminating }\end{array}$ & $\begin{array}{l}\text { Proportion } \\
\text { Surviving }\end{array}$ & $\begin{array}{l}\text { Cumulative } \\
\text { Proportion } \\
\text { Surviving } \\
\text { at End of } \\
\text { Interval }\end{array}$ \\
\hline 0 & 369 & 0 & 369.000 & 0 & .00 & 1.00 & 1.00 \\
\hline 1 & 369 & 0 & 369.000 & 2 & .01 & .99 & .99 \\
\hline 2 & 367 & 0 & 367.000 & 214 & .58 & .42 & .41 \\
\hline 3 & 153 & 0 & 153.000 & 116 & .76 & .24 & .10 \\
\hline 4 & 37 & 0 & 37.000 & 23 & .62 & .38 & .04 \\
\hline 5 & 14 & 1 & 13.500 & 0 & .00 & 1.00 & .04 \\
\hline 6 & 13 & 1 & 12.500 & 0 & .00 & 1.00 & .04 \\
\hline 7 & 12 & 0 & 12.000 & 0 & .00 & 1.00 & .04 \\
\hline 8 & 12 & 1 & 11.500 & 0 & .00 & 1.00 & .04 \\
\hline 9 & 11 & 0 & 11.000 & 0 & .00 & 1.00 & .04 \\
\hline 10 & 11 & 0 & 11.000 & 0 & .00 & 1.00 & .04 \\
\hline 11 & 11 & 2 & 10.000 & 0 & .00 & 1.00 & .04 \\
\hline 12 & 9 & 3 & 7.500 & 0 & .00 & 1.00 & .04 \\
\hline 13 & 6 & 0 & 6.000 & 0 & .00 & 1.00 & .04 \\
\hline 14 & 6 & 2 & 5.000 & 0 & .00 & 1.00 & .04 \\
\hline 15 & 4 & 1 & 3.500 & 0 & .00 & 1.00 & .04 \\
\hline 16 & 3 & 1 & 2.500 & 0 & .00 & 1.00 & .04 \\
\hline 17 & 2 & 1 & 1.500 & 0 & .00 & 1.00 & .04 \\
\hline 18 & 1 & 0 & 1.000 & 0 & .00 & 1.00 & .04 \\
\hline 19 & 1 & 1 & .500 & 0 & .00 & 1.00 & .04 \\
\hline
\end{tabular}

\section{Factors associated with early recovery time of women delivered by CS}

Multivariable Cox regression was carried out for variables verified as significant at $p=$ value,$<0.25$ during bivariate Cox regression. Accordingly, after adjusting for different variables ANC follow-up and discharge form the wound site were found to be independent predictors of recovery time in women delivered by CS at HU-CSH. Accordingly, women who had ANC follow-up were 1.5 times more likely to recover early as 
compared to thier conuter parts (AHR $=1.49,95 \%, \mathrm{Cl}: 1.05-2.10)$. On the other hand women who had discharge from the wound site had $87 \%$ reduced chance of early recovery time than those women who did not have dischagre from the wound site (AHR $=0.13,95 \%, \mathrm{Cl}: 0.03-0.56)$ (Table 5). 
Table 5

Output of Bivariable and Multivariable Cox regression analyses on factors associated with time-to-recovery after CS delivery among women who gave birth by CS delivery at HUCSH, 2020.

\begin{tabular}{|c|c|c|c|c|}
\hline \multirow[t]{3}{*}{ Variables } & \multicolumn{2}{|l|}{ Outcome } & \multirow{3}{*}{$\begin{array}{l}\text { CHR } \\
(95 \% \mathrm{Cl})\end{array}$} & \multirow{3}{*}{$\begin{array}{l}\text { AHR } \\
(95 \% \mathrm{Cl})\end{array}$} \\
\hline & \multirow{2}{*}{$\begin{array}{l}\text { Early recovered } \mathrm{N} \\
\text { (\%) }\end{array}$} & Censored & & \\
\hline & & N (\%) & & \\
\hline \multicolumn{5}{|l|}{ Age in years } \\
\hline$\leq 30$ & $326(91.8)$ & $7(50)$ & $1.47(1.09-2.16)$ & $1.07(0.72-1.18)$ \\
\hline$\geq 31$ & $29(8.2)$ & $7(50)$ & 1 & 1 \\
\hline \multicolumn{5}{|l|}{ Residence } \\
\hline Rural & $57(16.1)$ & $5(35.7)$ & $0.97(0.73-1.29)$ & - \\
\hline Urban & 298(83.9) & $9(64.3)$ & 1 & - \\
\hline \multicolumn{5}{|l|}{ Occupation } \\
\hline Employeed & 131 (39.9) & $6(42.9)$ & 1 & \\
\hline Unemployeed & $224(63.1)$ & $8(57.1)$ & $1.00(0.80-1.24)$ & \\
\hline \multicolumn{5}{|c|}{ Source of referral } \\
\hline No & $87(24.5)$ & $1(7.1)$ & $1.13(0.89-1.44)$ & $1.02(0.79-1.31)$ \\
\hline Yes & 268 (73.6) & $13(92.9)$ & 1 & 1 \\
\hline \multicolumn{5}{|l|}{ ANC visit } \\
\hline Yes & 317 (89.3) & $3(21.4)$ & $1.78(1.26-2.51)$ & $1.49(1.05-2.10)^{\star}$ \\
\hline No & 38 (10.7) & 11(78.6) & 1 & 1 \\
\hline \multicolumn{5}{|c|}{ Prolonged labor } \\
\hline Yes & 105 (29.6) & $2(14.3)$ & $1.08(0.86-1.36)$ & \\
\hline No & $250(70.4)$ & $12(85.7)$ & 1 & \\
\hline \multicolumn{5}{|l|}{ Abortion } \\
\hline Yes & $49(13.8)$ & $2(14.3)$ & $1.03(0.76-1.39)$ & \\
\hline No & 306 (86.2) & 12 (85.7) & 1 & \\
\hline \multicolumn{5}{|l|}{ Anemia } \\
\hline Yes & 67 (18.9) & $4(28.6)$ & $0.85(0.65-1.11)$ & $0.98(0.74-1.29)$ \\
\hline No & 288 (81.1) & $10(71.4)$ & 1 & 1 \\
\hline
\end{tabular}




\begin{tabular}{|c|c|c|c|c|}
\hline \multirow[t]{2}{*}{ Variables } & \multicolumn{2}{|l|}{ Outcome } & \multirow{2}{*}{$\begin{array}{l}\text { CHR } \\
(95 \% \mathrm{Cl})\end{array}$} & \multirow{2}{*}{$\begin{array}{l}\text { AHR } \\
(95 \% \mathrm{Cl})\end{array}$} \\
\hline & $\begin{array}{l}\text { Early recovered } \mathrm{N} \\
(\%)\end{array}$ & $\begin{array}{l}\text { Censored } \\
\mathrm{N}(\%)\end{array}$ & & \\
\hline \multicolumn{5}{|c|}{ Gestational age at CS } \\
\hline Term & 245 (69) & $2(14.3)$ & $1.24(0.99-1.56)$ & $1.13(0.89-1.12)$ \\
\hline Pre \& post term & $110(31)$ & $12(85.7)$ & 1 & 1 \\
\hline \multicolumn{5}{|l|}{ Previous CS } \\
\hline Yes & $47(13.2)$ & $10(71.4)$ & $0.71(0.52-0.97)$ & $0.87(0.64-1.20)$ \\
\hline No & $308(86.8)$ & $4(28.6)$ & 1 & 1 \\
\hline \multicolumn{5}{|c|}{ Discharge wound site } \\
\hline Yes & $2(0.5)$ & $9(64)$ & $\begin{array}{l}0.09(0.024- \\
0.38)\end{array}$ & $\begin{array}{l}0.13(0.03- \\
0.56)^{\star \star}\end{array}$ \\
\hline No & 353 (99.5) & $5(36)$ & 1 & 1 \\
\hline \multicolumn{5}{|c|}{ Types skin incision } \\
\hline Transvers & 339 (95.5) & $10(71.4)$ & $1.59(0.97-2.59)$ & $1.55(0.58-4.09)$ \\
\hline Vertical & $16(4.5)$ & $4(28.6)$ & 1 & 1 \\
\hline \multicolumn{5}{|c|}{$\begin{array}{l}\text { Type of anesthesia } \\
\text { used }\end{array}$} \\
\hline General & $15(4.2)$ & $8(57.1)$ & $0.49(0.30-0.81)$ & $1.31(0.46-3.71)$ \\
\hline Local & 340 (95.8) & $6(42.9)$ & 1 & 1 \\
\hline \multicolumn{5}{|l|}{ Chronic disease } \\
\hline Yes & $42(11.8)$ & $12(85.7)$ & $0.70(0.50-0 ; 97)$ & $0.92(0.66-1.29)$ \\
\hline No & 313 (88.2) & $2(14.3)$ & 1 & 1 \\
\hline \multicolumn{5}{|l|}{ PROM } \\
\hline Yes & $4(1.1)$ & $5(35.7)$ & $0.29(0.11-0.79)$ & $0.65(0.23-1.83)$ \\
\hline No & 351 (98.9) & $9(64.3)$ & 1 & 1 \\
\hline
\end{tabular}

On the other hand, time-to-recovery patterns of the women delivered by CS across selected variables were compared using Log-rank test. Hence, there were significantly different recovery rates among women with and without PROM. The mean recovery time with the presence and absence of PROM in women was 7.66 and 2.86 days respectively and their difference was statistically significant (Log-rank test $=18.659, P<$ 0.001). Similarly, women who received general and spinal anesthesia (Log rank test $=25.663, P<0.001$ ) and 
women who had and had not discharge from the wound site (Log-rank test $=48.623, P<0.001)$ had statistically significant difference in the recovery times (Table 6). 
Table 6

Log rank (Mantel-Cox) test for association of explanatory variables with time-to-recovery after CS delivery among women who gave birth by CS delivery at HUCSH, 2020.

\begin{tabular}{|c|c|c|c|}
\hline \multirow[t]{2}{*}{ Variables } & \multirow[t]{2}{*}{ Mean recovery time $(95 \% \mathrm{Cl})$} & \multicolumn{2}{|c|}{ Over all comparison Log Rank } \\
\hline & & $x^{2}$ & P-value \\
\hline PROM & $7.66(4.49-10.83)$ & 18.659 & $<0.001$ \\
\hline Yes & $2.86(2.59-3.14)$ & & \\
\hline \multicolumn{4}{|l|}{ No } \\
\hline Age & $2.75(2.52-2.98)$ & 11.357 & 0.001 \\
\hline$\leq 30$ & $5.69(3.55-7.83)$ & & \\
\hline \multicolumn{4}{|l|}{$\geq 31$} \\
\hline Discharge from wound site & $15.90(12.03-19.78)$ & 48.623 & $<0.001$ \\
\hline Yes & $2.62(2.46-2.79)$ & & \\
\hline \multicolumn{4}{|l|}{ No } \\
\hline Previous CS & $4.98(3.53-6.42)$ & 12.767 & $<0.001$ \\
\hline Yes & $2.67(2.44-2.88)$ & & \\
\hline \multicolumn{4}{|l|}{ No } \\
\hline Gestational age at CS & $2.55(2.38-2.72)$ & 10.15 & 0.001 \\
\hline Term & $4.09(3.21-4.97)$ & & \\
\hline \multicolumn{4}{|l|}{ Pre \& post-term } \\
\hline Chronic disease & $5.98(4.12-7.84)$ & 12.445 & $<0.001$ \\
\hline Yes & $2.56(2.42-2.71)$ & & \\
\hline \multicolumn{4}{|l|}{ No } \\
\hline Type of skin incision & $2.94(2.61-3.21)$ & 11.120 & 0.001 \\
\hline Transverse & $5.55(3.01-8.06)$ & & \\
\hline \multicolumn{4}{|l|}{ Vertical } \\
\hline Type of anesthesia & $8.26(5.05-11.47)$ & 25.663 & $<0.001$ \\
\hline General & $2.66(2.48-2.84)$ & & \\
\hline Local & & & \\
\hline
\end{tabular}




\begin{tabular}{|llll|}
\hline Variables & Mean recovery time(95\% Cl) & \multicolumn{2}{l|}{ Over all comparison Log Rank } \\
\cline { 2 - 4 } & & $\mathrm{X}^{2}$ & P-value \\
\hline ANC Visit & $2.56(2.39-2.73)$ & 32.139 & $<0.001$ \\
Yes & $6.30(4.38-8.22)$ & & \\
No & & & \\
\hline
\end{tabular}

\section{Discussion}

The finding of this study revealed that the overall proportion of timely recovery (within 4 days) after a maximum of 19 days is $96.2 \%$ [95\% Cl: $94.04-98.4 \%$ ]. The median (IQR) time of recovery was $2.00(2,3)$ days. The overall incidence density rate (IDR) of recovery in the cohort was 0.34 per Person-days or 2.38 per person-week. On the other hand the overall mean survival time was $3.07(95 \% \mathrm{Cl}$ : $2.75-3.40)$ days. Women who had ANC follow-up and discharge from the wound site were identified as significant positive and negative predictors of time-to- recovery after CS delivery respectively.

The finding of this study revealed that early recovery rate of $96.2 \%$, which is similar to WHO recommended average stay 3-4 days in hospital after a CS delivery [13]. The result of this study is in line with other similar study conducted in Ethiopia: Butajira and Attat hospitals [12]. However, the result is lower than a large population based study conducted in the North-Eastern Italy, where the recovery-time was 4.7 days [15] and in India, the recovery-time was 8.6 days [16]. The most likely reason for the similarity of the recovery rate might be due to the participants socio-demographic chracteristics, and the health care providers who performed the CS. Moreover, the hospitals are serving as a teaching institutions and lower rates of most comorbid conditions. Four years back a study conducted at the same hospital found that amongst the total mothers underwent CS, 65(11.0\%) developed surgical site infection [1]. However, in our study, only 11 (3\%) of women were developed surgical site infection. This shows the progress of quality service delivery of the hospital.

On the other hand, our study found that the median (IQR) time of recovery-time was $2.00(2,3)$ days. This is corroborated by studies conducted outside Ethiopia, where the avarage of the women were discharged within 2 days $[13,17]$. However, the finding of this study was inconsistent with other study conducted in Ethiopia: Butajira and Attat hospitals where the mean recovery time was 3.27 [12] and a study conducted in 30 low and mid-income countries showed that the mean ( \pm SD) hospitalization after cesarean section was 5.9 ( \pm 3.4$)$ days in the studied localities [18]. This implies that, the study hospital has an improved and quality of pre, intra and post-operative services which help the women to recover early. Moreover, all the women underwent CS at the study hospital were discharged alive; this indicates that the quality of the procedure was at optimal level.

In this study we used Log-rank test to see the patterns of time-to-recovery after CS for selected variables. We found that the mean time-to-recovery among women whose age were $\leq 30$ and $\geq 31$ years was 2.75 and 5.69 days respectively ( $\log$ rank test $=11.357, P=0.001$ ). The same finding was reported by different 
studies where younger women were discharged earlier $[3,11,17,18]$. This might be due to the fact that, an increased age has been associated with different comorbidities which affects the length of stay at hospital. Similarly women who had had and had not had chronic disease had statistically significant difference in the recovery times (Log-rank test $=12.445, P<0.001$ ). This result is supported by different studies; the hospital stay of women with complications and comorbidities was longer $[1,15,17,18]$. This is due to the reason that women with complications and/or with co-morbities needs additional service for the mnagement. So, this might prolongs her length of stay at hospital. Moreover, the study hospital is serving as referral for the surrounding and adjacent woredas and zones of Oromia region and Gedio Zones catchment populations. This could over estimated the number of complicated mothers.

Our study revelaed that the women who have discharge from the wound site had $87 \%$ reduced recovery time than those women who did not have dischagre from the wound site (AHR $=0.13,95 \%, \mathrm{Cl}$ : 0.03-0.56). This finding is supported by studies conducted in Ethiopia [1,11]. Another study conducted in England found that women undergoing CS are at higher risk of developing postnatal infection and this makes the recovery time longer [4]. Evidence suggested that the occurrence of surgical site infection is expected to increase as the incidence of CS increases [9]. The magnitude of wound infection (2.9\%) found in this study hospital is comparable to the global guidelines for prevention of surgical infection (2.9\%) following cesarean section delivery [6]. This implies improvements in hygiene conditions, antibiotic prophylaxis, sterile procedures, and other practices in our study hospital. However, still women undergoing a CS had better to be equipped with pertinent information on how to keep the surgical site clean, post-operative recovery and infection prevention advices.

Use of ANC designed to guide and support women on the mode of birth after a primary caesarean delivery have been found to be advantageous [19]. Accordingly, our study found that, women who had ANC followup were 1.5 times more likely to recover early as compared to thier counter parts $(\mathrm{AHR}=1.49,95 \%, \mathrm{Cl}$ : 1.05-2.10). This result is by supported another study that reported, ANC and correctly indicated CS can positively impact on health outcomes of the mother [20].

The possible reason might be due to the that fact that during ANC follow-up women's with a previous caesarean birth, chronic diseases and women with pregnancy related complications could be identified and decision for mode of birth could be agreed upon by the woman preference.

This study has added weight to the existing literature by quantifying the time-to-recovery following cesarean section delivery; as a result it could be used as an input for policymakers and health program developers on maternal health services. Nevertheless, the findings from this study would be difficult to infer to the wider population, because the study was hospital, HUCSH is tertiary type of hospital which is serving as a teaching institution for different disciplines including specialties. So this might positively affect the quality of the services given to the mothers unlike that of the general and primary hospitals where scare obstetrics and gynecologist found. Moreover, the sample were relatively small, some of the variable, such as qualification of person performed the CS, type of health facility where the CS performed as we have included the referral cases were not assessed. 


\section{Conclusions}

The rate of early recovery and the median (IQR) time of recovery obtained by this study are comparable to the global level figures. The overall incidence density rate (IDR) of recovery in the cohort was 0.34 per Person-days or 2.38 per person-week. Women who had ANC follow-up and discharge from the wound site were identified as a positive and negative predictors of time-to- recovery after CS delivery respectively. The HUCSH Obestetrics and gynecology department should stress on women undergone CS want more information on what constitutes a 'normal' post-operative recovery and keeps the cleanness of the surgical site to prevent the incidence of postsurgical site infection which is the major predictor for time-to-recovery after CS delivery. The STROBE guideline was used to ensure the reporting of this cross-sectional study

\section{Abbreviations}

ACOG: American College of Obstetrician and Gynecologists

AHR: Adjusted Hazard Ratio

BMI: Body Mass Index

CDs: Cesarean Delivery

Cl: Confidence Intervals

CHR Crude Hazard Ratio

CS: Cesarean Section

HIV Human Immune Deficiency Virus

HUCSH: Hawassa University Comprehensive Specialized Hospital

IQR Inter Quartile Range

PROM: Pre-mature Rapture of Membrane

SPSS: Statistical Package for Social Science

SSI: Surgical Site Infection

WHO: World Health Organization

\section{Declarations}

\section{Ethics approval and consent to participate}


Ethical approval was obtained from the Institutional Review Board of Pharma College, School of graduate studies department of Public Health. Additional official letter of corroborate was also obtained from HUCSH Chief executive Office. All the participants were approached immediate to delivery by the data collectors and invited to participate in the study voluntarily and took informed verbal consent from each mother before data collection. The ethical review committee had approved our verbal consent procedure. No human participants under the age of 18 years were included in this study as a result no informed consent were obtained from a parent and/or legal guardian. Moreover, information regarding any specific personal identifiers like name of the participants was not collected and also confidentiality of any personal information were also maintained. All methods were performed in accordance with the relevant ethical guidelines and regulations.

\section{Consent for publication}

"Not applicable"

\section{Availability of data and materials}

Data essential for the conclusion are included in this manuscript. Additional data can be obtained from the corresponding author on a reasonable request.

\section{Competing interests}

"The authors declare that they have no competing interests"

\section{Funding}

Pharma College has funded the research. The funding institution had no part in study design, information gathering, and analysis, judgment to publish, or development of the manuscript.

\section{Authors' contributions}

AF RZ DH conceptualized the paper, conducted the data collection process, and analyzed the data. AF wrote the draft of the manuscript. AF RZ, HB, WS DH, revised and edited the manuscript draft. All authors read and approved the final manuscript.

\section{Acknowledgements}

We would like to acknowledge Hawassa University Comprehensive Specialized Hospital for permitting us to undertake this study. We are also grateful for Pharma College Hawassa Campus for the financial 
support of the study. Our thanks also go to our study participants, data collectors, supervisors and those who were actively participated in our study.

\section{References}

1. WHO recommendations non-clinical interventions to reduce unnecessary caesarean sections. 2018, World Health Organization

2. WHO Statement on Caesarean Section Rates. 2015, World Health Organization Avenue Appia 20, CH1211 Geneva 27, Switzerland.

3. Deaths from caesarean sections 100 times higher in developing countries: global study Outcomes for women " far worse" than expected. 2019 [cited 2021 March 20]; Available from: https://www.who.int/reproductivehealth/death-from-caesarean-sections/en/.

4. Weckesser, A., et al., Women's perspectives on caesarean section recovery, infection and the PREPS trial: a qualitative pilot study. BMC Pregnancy and Childbirth, 2019. 19(245).

5. Halil, H.M., et al., Predictors of Cesarean Section among Women Delivered at Durame General Hospital, Southern Ethiopia. Journal of Women's Health Care, 2020. 9(482).

6. Global guidelines for the prevention of surgical site infection, second edition. 2018, World Health Organization Geneva.

7. Patel, S., et al., Obstetric and perinatal outcome in previous one cesarean section. Int J Reprod Contracept Obstet Gynecol. www.ijrcog.org, 2016. 5(9): p. 3141-3146.

8. Begum, T., et al., Indications and determinants of caesarean section delivery: Evidence from a population- based study in Matlab, Bangladesh. PLoS ONE 2017. 12(11).

9. Zuarez-Easton, S., et al., Postcesarean wound infection: prevalence, impact, prevention, and management challenges. International Journal of Women's Health, 2017. 9: p. 81-88.

10. Wodajo, S., M. Belayneh, and S. Gebremedhin, Magnitude and Factors Associated With Post-Cesarean Surgical Site Infection at Hawassa University Teaching and Referral Hospital, Southern Ethiopia: A Cross-sectional Study. Ethiopian Journal of Health Sciences May 2017. 27(3 ).

11. Lijaemiro, H., S.B. Lemlem, and J.T. Deressa, Incidence of Surgical Site Infection and Factors Associated among Cesarean Deliveries in Selected Government Hospitals in Addis Ababa, Ethiopia, 2019. Hindawi Obstetrics and Gynecology International, 2020.

12. Lamada, K.L., et al. Time to recovery after cesarean section delivery and its predictors in Butajira and Attat hospitals, south Ethiopia: a prospective cohort study in Impacts of Climate Change on Public Health: Ethiopia's Challenge in the 21st Century. 2019. Adama: Ethiopian Public Health Association (EPHA).

13. Jerome J. Federspiel, unitha C. Suresh, and L.M. Szymanski, Hospitalization Duration Following Uncomplicated Cesarean Delivery: Predictors, Facility Variation, and Outcomes. AJP Rep. , Apr, 2020 10(2).

14. Fikrie, A., Alemayehu A, and Gebremedhin S., Treatment outcomes and factors affecting time-torecovery from severe acute malnutrition in 6-59 months old children admitted to a stabilization center 
in Southern Ethiopia: A retrospective cohort study. Italian Journal of Pediatrics, 2019. 45(46): p. 2-9.

15. Cegolon, L., et al., Length of stay following cesarean sections: A population based study in the Friuli Venezia Giulia region (North-Eastern Italy), 2005-2015. PLoS ONE, 2019. 14(2).

16. Kumar, P. and P. Dhillon, Length of stay after childbirth in India: a comparative study of public and private health institutions. BMC Pregnancy and Childbirth, 2020. 20(181).

17. Pereiral, S.L., et al., Factors associated with the length of hospital stay of women undergoing cesarean section. Rev Saude Publica, 2019. 53(65).

18. Campbell, O.M.R., et al., Length of Stay After Childbirth in 92 Countries and Associated Factors in 30 Low- and Middle-Income Countries: Compilation of Reported Data and a Cross-sectional Analysis from Nationally Representative Surveys. PLoS Med 2015. 13(3).

19. Gupta, J., G. Smith, and M.R. Chodankar, Birth After Previous Caesarean Birth. Green-top Guideline No. 45. October 2015, Royal College of Obstetricians and Gynaecologists. p. 31.

20. Barros, A.J., et al., Antenatal care and caesarean sections: trends and inequalities in four populationbased birth cohorts in Pelotas, Brazil, 1982-2015. International Journal of Epidemiology, 2019. 48(1). 